\title{
Геохимия арктического горного озера в условиях загрязнения стоками апатит-нефелинового производства
}

Даувальтер В.А. ${ }^{1}$, Слуковский 3.И. ${ }^{1,2}$, Денисов Д.Б. ${ }^{1}$, Гузева А.В. ${ }^{3}$

${ }^{1}$ Институт проблем промышиленной экологии Севера Кольского НЦ РAH, Anamumbl, v.dauvalter@ksc.ru

${ }^{2}$ Институт геологии Карельского НЦ РАН, Петрозаводск, slukovsky87@gmail.com

${ }^{3}$ Институт озероведения РАН, Санкт-Петербург, оlina2108@mail.ru

Аннотация. В результате геохимических исследований озера Большой Вудъявр установлено, что поступление стоков апатит-нефелинового производства привело к значительным экологическим последствиям. В толще воды оз. Б. Вудъявр прослеживается четкая вертикальная гидрохимическая стратификация вследствие распределения потоков воды в разных слоях от двух главных притоков. По поверхности озера распространяются низкоминерализованные воды из р. Вудъяврйок, а в придонных слоях озера движутся минерализованные воды р. Юкспоррйок, загрязненные стоками добычи апатит-нефелиновых руд. Содержание главных ионов, соединений азотной и фосфорной группы и некоторых микроэлементов в придонном слое воды оз. Б. Вудъявр выше в 2-3 раза по сравнению с поверхностным слоем. Установлено, что все элементы, связанные с добычей и переработкой апатит-нефелиновых руд, находятся в повышенных концентрациях в поверхностных слоях донных отложений оз. Б. Вудъявр. Основными формами содержания элементов в донных отложениях является минеральные труднодоступные формы.

Ключевые слова: Арктика, антропогенная нагрузка, гидрохимия, геохимия, загрязнение, горные озера, поверхностные воды, донные отложения, горная промышленность.

\section{Geochemistry of an arctic mountain lake under conditions of wastewater pollution from apatite-nepheline production}

\author{
Dauvalter V.A. ${ }^{1}$, Slukovskii Z.I. ${ }^{1,2}$, Denisov D.B. ${ }^{1}$, Guzeva A.V. ${ }^{1,3}$ \\ ${ }^{1}$ Institute of North Industrial Ecology Problems Kola SC RAS, Apatity,v.dauvalter@ksc.ru \\ ${ }^{2}$ Institute of Geology of Karelian Research Centre of RAS, Petrozavodsk, slukovsky87@gmail.com \\ ${ }^{3}$ Institute of Limnology of RAS, Saint Petersburg, olina2108@mail.ru
}

\begin{abstract}
As a result of geochemical studies of Lake Bolshoy Vudjavr, it was established that effluents from the apatite-nepheline production has led to significant environmental consequences. The clear vertical hydrochemical stratification is traced in the water column of Lake Bolshoy Vudjavr due to the distribution of water flows in different layers from the two main tributaries. Low-salinity waters from River Vudjavrjok spread over the lake surface, and saline waters of River Juksporrjok, polluted by the discharge of apatite-nepheline ores, move in the bottom lake layers. The content of the basic ions, nutrients and some trace elements in the bottom water layers of Lake Bolshoy Vudjavr is 2-3 times higher than in the surface layers. It was found that all elements associated with the extraction and processing of apatite-nepheline ores are in high concentrations in the surface layers of sediments of Lake Bolshoy Vudyavr. The main forms of the content of elements in sediments are mineral insoluble forms.
\end{abstract}

Key words: Arctic, anthropogenic load, hydrochemistry, geochemistry, pollution, mountain lakes, surface waters, sediments, mining.

\section{Введение}

Озеро Большой Вудъявр (далее по тексту оз. Б. Вудъявр) является самым крупным внутренним водоемом Хибинского щелочного горного массива, хотя относиться к классу небольших озер (1-10 км²). Озеро занимает впадину среди окружающих его гор. Абсолютная отметка озера равна 312 м. Площадь его водной поверхности составляет 3.9 км², объем воды -0.0579 км$^{3}$, наибольшая глубина -37.6 м. Длина озера около 2 км, ширина - около 1.5 км.

Промышленное освоение региона началось со строительства Мурманской железной дороги, которая позволила осуществить геолого-разведывательные экспедиции и положила начало освоению минеральных ресурсов региона. Результатом рекогносцировочных геологических съемок 
1920-1923 гг. под руководством академика А.Е. Ферсмана стало открытие в Хибинском горном массиве крупнейших в мире апатит-нефелиновых месторождений с огромными запасами фосфорного сырья. В 1929 г. был организован производственный трест «Апатит», который на протяжении десятилетия являлся основной организацией, осуществляющей освоение минеральных ресурсов Хибин. С 1931 г. на берегу оз. Б. Вудъявр началась переработка апатитовой руды на обогатительной фабрике (АНОФ-І). Именно с этого времени в оз. Б. Вудъявр и далее по р. Б. Белая начали поступать без очистки сточные воды.

\section{Материалы и методы}

С целью изучения влияния стоков добычи и переработки апатит-нефелиновых руд на химический состав воды и донных отложений (ДО) озера Б. Вудъявр в апреле 2018 г. сотрудниками ИППЭС КНЦ РАН были проведены исследования. Пробы воды с поверхностного слоя (1 м от поверхности), глубины 5 м и далее с шагом 5 м до дна отбирались в центральной части озера на акватории с максимальной глубиной 2-х литровым пластиковым батометром. Колонка ДО была отобрана пробоотборником Limnos и разделена на слои по 1 см. Для определения валовых концентраций элементов проводилось разложение образцов ДО путем кислотного вскрытия с использованием $\mathrm{HF}, \mathrm{HNO}_{3}$ и $\mathrm{HCl}$ в открытой системе. Содержание 50 элементов в пробах ДО определяли масс-спектральным методом на приборе XSeries-2 ICP-MS (Thermo Ficher Scientific). Химический состав воды и ДО определяли в центре коллективного пользования ИППЭС Кольского НЦ РАН по единым методикам (Даувальтер, 2012; Методы..., 2019).

\section{Результаты и обсуждение}

В толще воды оз. Б. Вудъявр прослеживается четкая вертикальная стратификация вследствие распределения потоков воды в разных слоях от двух главных притоков - по поверхности озера распространяются низкоминерализованные воды из р. Вудъяврйок, а в придонных слоях озера движутся более минерализованные воды р. Юкспоррйок, загрязненные рудничными стоками добычи апатит-нефелиновых руд АО «Апатит». Главным рудным минералом Хибинских месторождений является фторапатит $\left(\mathrm{Ca}_{5}\left(\mathrm{PO}_{4}\right)_{3} \mathrm{~F}\right)$, который при выветривании поставляет в оз. Б. Вудъявр соединения P, Ca, F, Ti, Th, а также редкоземельные элементы (РЗЭ) и другие микроэлементы (Ферсман, 1968). В поверхностном слое зафиксировано нейтральное значение величины $\mathrm{pH}$, а глубже находятся слабощелочные и щелочные воды (рис. 1).

Минерализация воды, содержание главных ионов, соединений азотной и фосфорной группы, некоторых микроэлементов в придонном слое толщи воды оз. Б. Вудъявр выше в 2-3 раза по сравнению с поверхностным слоем (рис. 1-3). При добыче апатит-нефелиновых руд на АО «Апатит» используются азотсодержащие взрывчатые вещества, которые значительно увеличивают содержание азотных соединений (рис. 2). Несмотря на высокие концентрации биогенных элементов, содержание органических веществ (цветность, ХПК ${ }_{\mathrm{Mn}}$ и $\mathrm{C}_{\text {орг }}$, рис. 2) в оз. Б. Вудъявр меньше, чем в среднем в озерах Мурманской области (Кашулин и др., 2010) и озер северо-запада России (Никаноров, 2001).

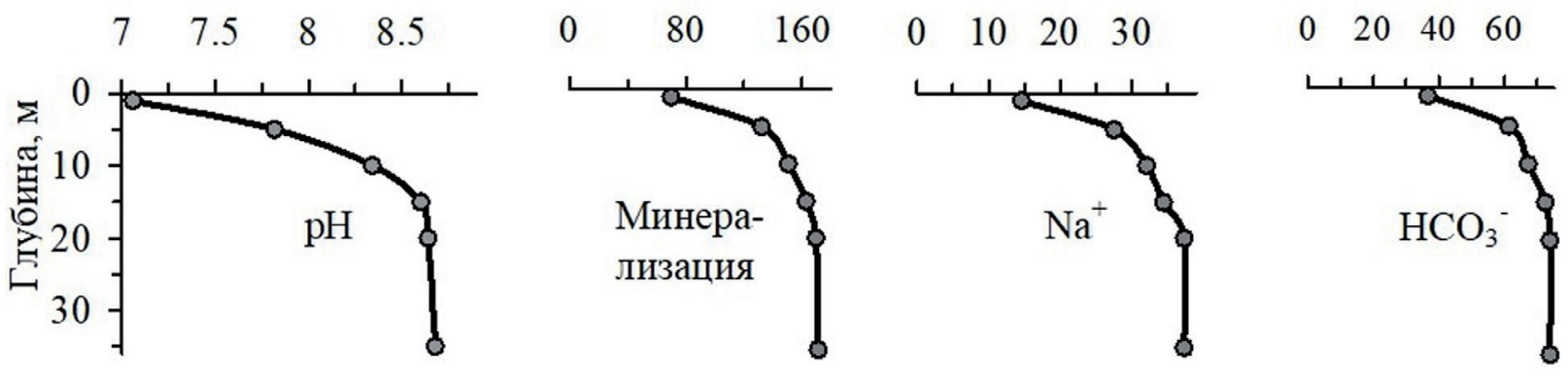

Рис. 1. Вертикальное распределение значений $\mathrm{pH}$, минерализации и главных ионов $\mathrm{Na}^{+}$и $\mathrm{HCO}_{3}^{-}$(мг/л) в водной толще оз. Б. Вудъявр.

Fig. 1. Vertical distribution of $\mathrm{pH}$ values, mineralization and main ions $\mathrm{Na}^{+}$and $\mathrm{HCO}_{3}^{-}(\mathrm{mg} / \mathrm{l})$ in the water column of Lake Bolshoy Vudjavr. 


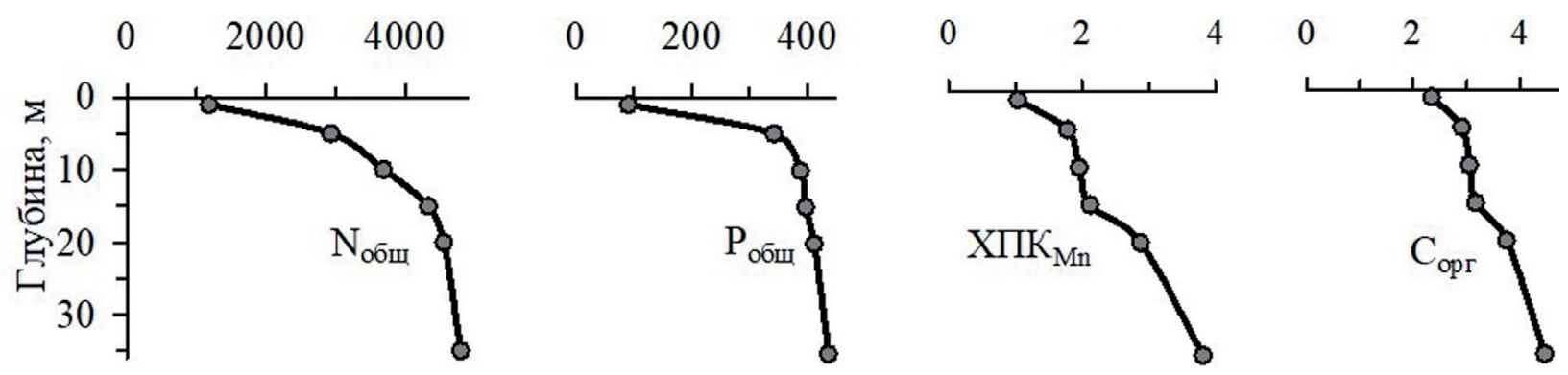

Рис. 2. Вертикальное распределение общего содержания биогенных элементов $\left(\mathrm{N}_{\text {общ }}\right.$ и $\mathrm{P}_{\text {общ }}$, мкг/л), химического потребления кислорода $\left(\mathrm{XПК}_{\mathrm{Mn}}\right)$ и органического углерода $\left(\mathrm{C}_{\text {орг }}\right)$ в водной толще оз. Б. Вудъявр.

Fig. 2. Vertical distribution of the total content of nutrients $\left(\mathrm{N}_{\text {tot }}\right.$ and $\left.\mathrm{P}_{\text {tot }}, \mu \mathrm{g} / \mathrm{l}\right)$, chemical oxygen demand $\left(\mathrm{COD}_{\mathrm{Mn}}\right)$ and organic carbon $\left(\mathrm{C}_{\text {org }}\right)$ in the water column of Lake Bolshoy Vudjavr.

Шахтные и рудничные стоки обогащают воду оз. Б. Вудъявр щелочными и щелочноземельными металлами (Ca, Na, K, Sr), соединениями N, P, Mn, Fe, Mo, Al (рис. 3). Рудным минералом является также нефелин, представляющий собой алюмосиликат калия и натрия $(\mathrm{Na}, \mathrm{K}) \mathrm{AlSiO}_{4}$, который в процессе выветривания обогащает природные воды щелочными металлами $\mathrm{Na}$ и $\mathrm{K}$, а также $\mathrm{Al}$ (рис. 3).
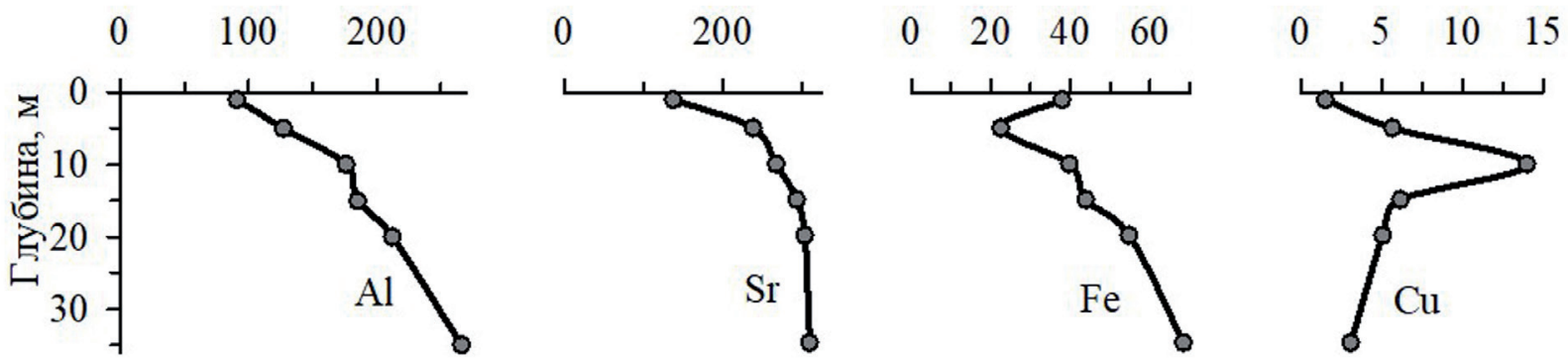

Рис. 3. Вертикальное распределение содержания микроэлементов (мкг/л) в водной толще оз. Б. Вудъявр.

Fig. 3. Vertical distribution of the content of trace elements $(\mu \mathrm{g} / \mathrm{l})$ in the water column of Lake Bolshoy Vudjavr.

В оз. Б. Вудъявр поступают стоки обогатительной фабрики и рудников $\mathrm{AO}$ «Апатит» с большим содержанием взвешенных веществ, а также тонко- и мелкодисперсные пылевые частицы горных пород, образующиеся после взрывов и в процессе погрузки и разгрузки раздробленного материала на рудниках. Поэтому все элементы (щелочные и щелочноземельные металлы, Р3Э, Р, Ti, Th), связанные с добычей и переработкой апатит-нефелиновых руд, находятся в повышенных концентрациях в поверхностных слоях ДО оз. Б. Вудъявр (рис. 4 и 5).

Подобное распределение РЗЭ было зафиксировано в ДО оз. Имандра в зоне поступления сточных вод АО «Апатит» (Даувальтер и др., 1999), но слой ДО с повышенными относительно фоновых значений содержаниями в оз. Имандра меньше в 2 раза $(10$ см), что говорит о меньшей скорости в нем осадконакопления. Влияние на формирование химического состава ДО оз. Б. Вудъявр оказывают также и выбросы комбината «Североникель», находящегося от озера на расстоянии менее 50 км, что сказалось в повышении концентраций тяжелых металлов $(\mathrm{Cu}, \mathrm{Ni}, \mathrm{Co}, \mathrm{Cd}, \mathrm{Pb}, \mathrm{Sn})$ к поверхности ДО (рис. 6). Анализ вертикального распределения химических элементов в колонке ДО оз. Б. Вудъявр мощностью 27 см установил значительное увеличение концентраций многих элементов в верхнем 20-см слое по сравнению с нижележащими слоями (рис. 4-6). Эти результаты полностью согласуются с ранее проводимыми исследованиями (Денисов и др., 2006).

Ранее проведенными исследованиями было установлено, что скорость осадконакопления в оз. Б. Вудъявр составляет примерно 2.3 мм/год (Слуковский и др., 2020). Подобная скорость осад- 

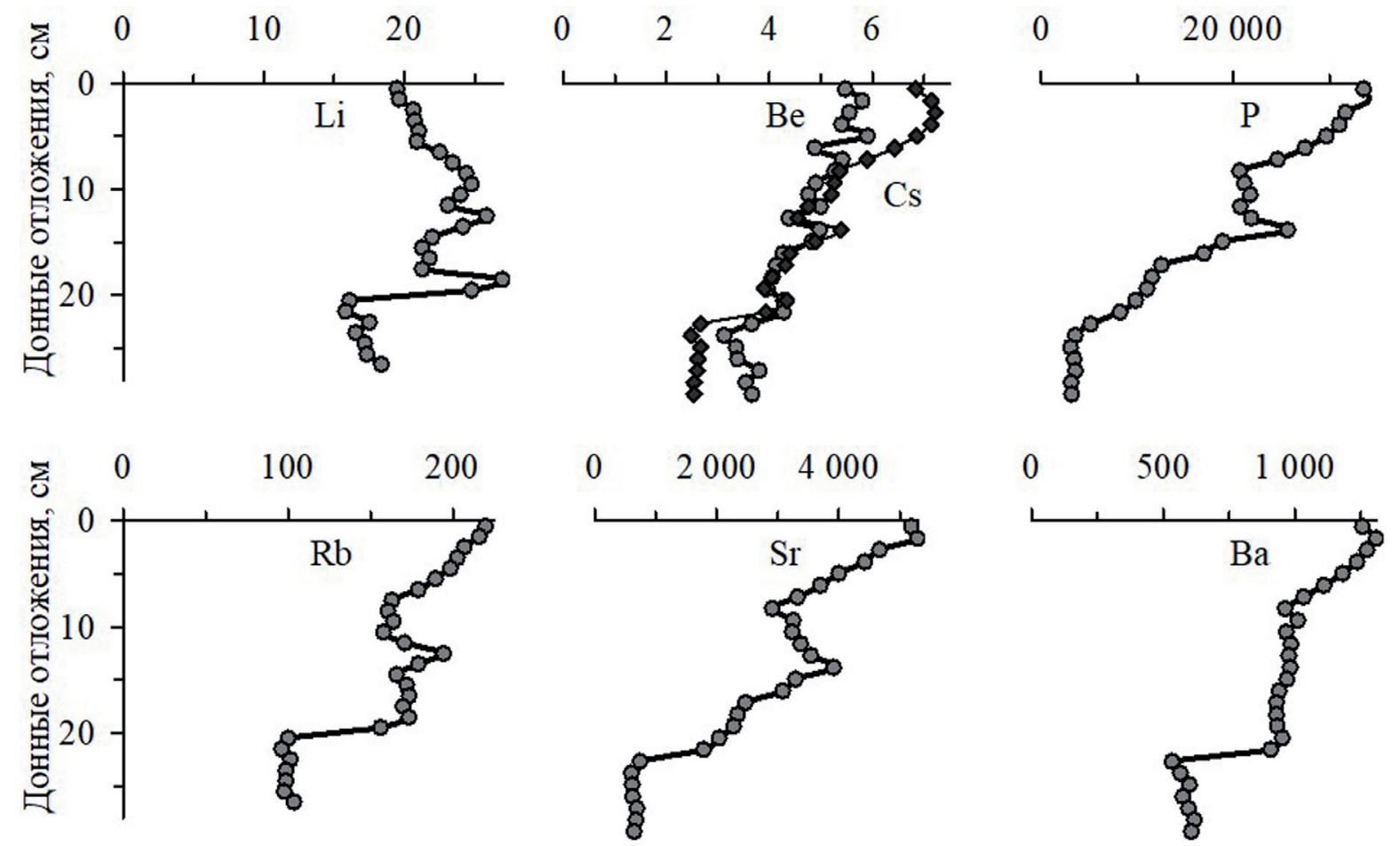

Рис. 4. Вертикальное распределение валовых концентраций (мкг/г) щелочных и щелочноземельных металлов и Р в ДО оз. Б. Вудъявр.

Fig. 4. Vertical distribution of total concentrations $(\mu \mathrm{g} / \mathrm{g})$ of alkali and alkaline earth metals and $\mathrm{P}$ in the sediments of Lake Bolshoy Vudjavr.

конакопления была выявлена в водоемах Мурманской области, получающих стоки добычи и переработки медно-никелевых руд - озера Имандра (1.5 мм/год, Моисеенко и др., 2002) и Куэтсъярви (1.5-3 мм/год, Dauvalter, 2003). Большая скорость осадконакопления в озерах Куэтсъярви и Б. Вудъявр связана, вероятно, с их меньшими размерами по сравнению с оз. Имандра - крупнейшим озером в Мурманской области.

Основной формой содержания тяжелых металлов в ДО является минеральная форма (до 70 \%), однако органическим веществом аккумулируется от 16 до 30 \% поступающих в озеро металлов (Слуковский и др., 2019, 2020). В самом верхнем слое ДО высока роль водорастворимой формы металлов (до $15 \%$ ).
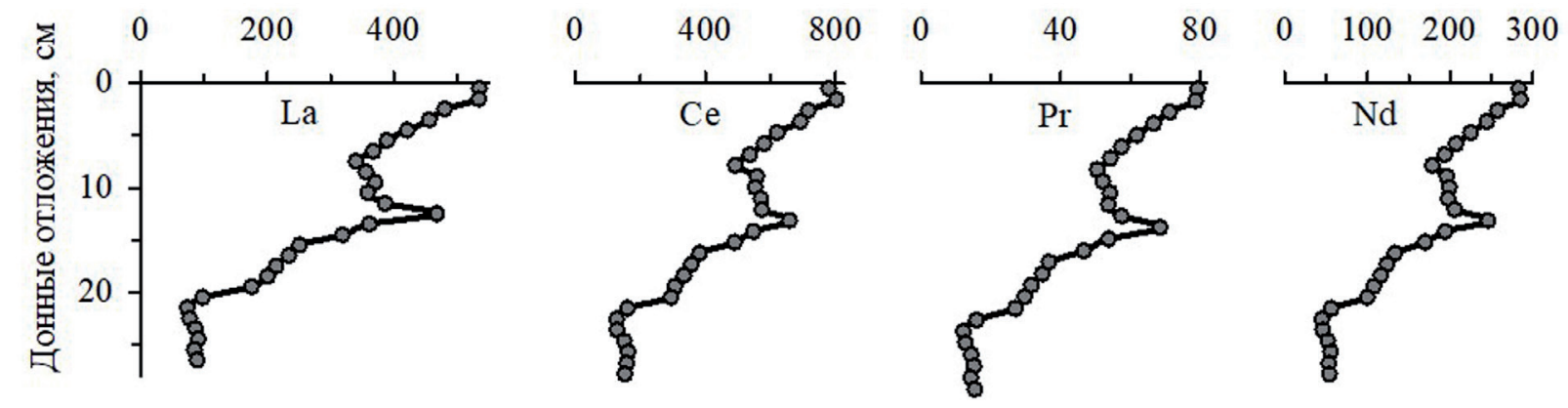

Рис. 5. Вертикальное распределение валовых концентраций (мкг/г) редкоземельных элементов в ДО оз. Б. Вудъявр.

Fig. 5. Vertical distribution of total concentrations $(\mu \mathrm{g} / \mathrm{g})$ of rare earth elements in sediments of Lake Bolshoy Vudjavr. 

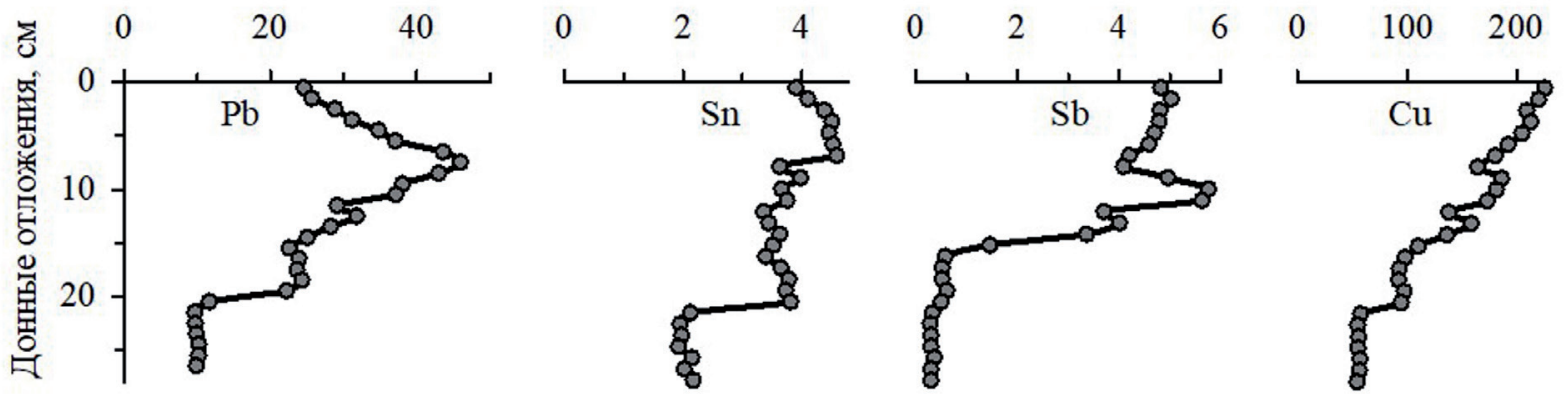

Рис. 6. Вертикальное распределение валовых концентраций (мкг/г) микроэлементов в ДО оз. Б. Вудъявр.

Fig. 6. Vertical distribution of total concentrations $(\mu \mathrm{g} / \mathrm{g})$ of trace elements in sediments of Lake Bolshoy Vudjavr.

\section{Выводы}

Химический состав воды оз. Б. Вудъявр претерпел значительные перемены вследствие трансформации гидрологического и гидрохимического режимов в результате поступления сточных вод промышленных предприятий АО «Апатит» и коммунально-бытовых стоков, застройки городской территории, прокладывания подземных и наземных коммуникаций, выведения части поверхностного стока из баланса водоемов. Значительно возросла минерализация воды оз. Б. Вудъявр, величина $\mathrm{pH}$, содержание соединений азота и фосфора. Установлена четкая вертикальная гидрохимическая стратификация вследствие распределения потоков воды от двух главных притоков оз. Б. Вудъявр, при которой гидрохимические показатели в придонном слое воды оз. Б. Вудъявр выше в 2-3 раза по сравнению с поверхностным слоем. Повышенные концентрации биогенных элементов в воде озера способствуют интенсивному развитию процессов эвтрофирования. Все элементы (щелочные и щелочноземельные металлы, РЗЭ, Р, Ti, Th), связанные с добычей и переработкой апатитнефелиновых руд, находятся в повышенных концентрациях в поверхностных слоях ДО оз. Б. Вудъявр. Основной формой содержания элементов в ДО является минеральная труднодоступная форма.

Работа выполнена в рамках темы НИР № 0226-2019-0045 (полевые работы) и поддержана из средств грантов РФФИ № 18-05-60125 (химический анализ) и РНФ № 19-77-10007 (определение форм нахождения металлов).

\section{Литература}

1. Даувальтер В.А., Моисеенко Т.И., Родюшкин И.В. Геохимия редкоземельных элементов в озере Имандра, Мурманская область // Геохимия. 1999. № 4. С. 376-383.

2. Даувальтер В.А. Геоэкология донных отложений озер. Мурманск. Изд-во: Мурманского гос. техн. унта. 2012. $242 \mathrm{c}$.

3. Денисов Д.Б., Даувальтер В.А., Кашулин Н.А., Каган Л.Я. Долговременные изменения состояния субарктических водоемов в условиях антропогенной нагрузки (по данным диатомового анализа) // Биология внутренних вод. 2006. № 1. С. 24-30.

4. Кашулин Н.А., Сандимиров С.С., Даувальтер В.А., Кудрявцева Л.П., Терентьев П.М., Денисов Д.Б., Валькова С.А. Аннотированный экологический каталог озер Мурманской области (Восточная часть. Бассейн Баренцева моря). В 2-х Ч. Апатиты. Изд-во: КНЦ РАН. 2010. Ч. 1. 249 с. Ч. 2. 128 с.

5. Методы экологических исследований водоемов Арктики. Мурманск. Изд-во: МГТУ. 2019. 180 с.

6. Никаноров А.М. Гидрохимия. СПб. Изд-во: Гидрометеиздат. 2001. 444 с.

7. Слуковский 3.И., Мицуков А.С., Даувальтер В.А. Молибден в донных отложениях озера Большой Вудъявр, Мурманская область: вертикальное распределение и формы нахождения // Труды Ферсмановской научной сессии ГИ КНЦ РАН. 2019. № 16. С. 534-538. https://doi.org/10.31241/FNS.2019.16.109.

8. Слуковский 3.И., Гузева А.В., Григорьев В.А., Даувальтер В.А., Мицуков А.С. Палеолимнологическая реконструкция техногенного воздействия на экосистему оз. Большой Вудъявр (Кировск, Мурманская область, Артика): новые геохимические данные // Экология урбанизированных территорий. 2020, № 4. C. 96-107. https://doi.org/10.24412/1816-1863-2020-4-96-107.

9. Ферсман А.Е. Наш апатит. М. Изд-во: Наука. 1968. 136 с.

10. Dauvalter V. Impact of mining and refining on the distribution and accumulation of nickel and other heavy metals in sediments of subarctic lake Kuetsjärvi, Murmansk region, Russia // Journal of Environmental Monitoring. 2003. V. 5 (2). P. 210-215. https://doi.org/10.1039/b301144p. 